\title{
Valvas Cardíacas Obtidas por Engenharia de Tecidos. A Mais Nova Geração de Próteses Biológicas
}

\author{
Pascal M. Dohmen, Francisco Diniz Affonso da Costa, Iseu de Santo Elias Affonso da Costa, \\ Wolfgang Konertz
}

Berlim, Alemanha - Curitiba, Pr

Anos de pesquisa permitiram criar, por engenharia de tecidos, uma válvula comparável a uma valva cardíaca nativa normo funcionante. Estudos em animais mostraram que próteses criadas por engenharia de tecidos, semeadas com células endoteliais, mostraram excelente comportamento hemodinâmico, sete dias, três e seis meses após o implante. Houve repopulação por células intersticiais em todas as próteses criadas por engenharia de tecidos, que aumentou ao longo do tempo. Sendo uma estrutura viva, tais próteses devem ter potencial de remodelação, regeneração e crescimento. Além disso, não foi vista calcificação após seu implante em carneiros jovens, o que constitui o modelo experimental mais comum para avaliar o comportamento de novas válvulas cardíacas postas em contato com o sangue.

Este novo tipo de válvula cardíaca já foi implantado nos primeiros pacientes com excelentes resultados imediatos. Será necessário acompanhamento para verificar sua evolução a médio e longo prazo.

\section{Introdução}

O número total de operações valvares em todo o mundo é de cerca de 170 mil por ano, sendo que, somente na Alemanha, é de aproximadamente $20 \mathrm{mil}^{1}$. Diferentes tipos de substitutos valvares estão disponíveis, podendo ser classificados em próteses mecânicas, heteroenxertos (montados com ou sem suporte, feitos com material porcino ou pericárdio bovino) e homoenxertos (convencionais ou decelularizados). Cada uma destas válvulas tem suas próprias vantagens e desvantagens.

A vantagem das próteses mecânicas é sua longa durabilidade e, as desvantagens, a anticoagulação permanente,

Hospital Charité, Universidade Humboldt, Berlim, Alemanha e Santa Casa de Misericórdia, Pontifícia Universidade Católica do Paraná, Curitiba

Correspondência: Francisco Diniz Affonso da Costa - Rua Henrique Coelho Neto, 55 82200-120 - Curitiba, PR - E-mail: fcosta@mps.com.br

Recebido para publicação em 12/11/01

Aceito em 18/2/02 com risco de complicações tromboembólicas ${ }^{2,3}$ e um desempenho hemodinâmico não fisiológico ${ }^{4}$. As vantagens das próteses biológicas são a dispensa de anticoagulação e o excelente desempenho hemodinâmico, com redução completa da hipertrofia ventricular em certos pacientes ${ }^{5} \mathrm{e}$, a desvantagem, a progressiva degeneração com o passar do tempo, especialmente em jovens ${ }^{6}$. As desvantagens dos homoenxertos são a discrepância entre a disponibilidade e a demanda, principalmente de homoenxertos pulmonares que, entretanto, oferecem excelentes resultados a longo prazo.

Infelizmente, estas válvulas não são estruturas vivas, de modo que não apresentam potencial de regeneração e crescimento. As válvulas obtidas por engenharia de tecidos devem superar essas desvantagens e mostrar excelente desempenho hemodinâmico e maior durabilidade ${ }^{7,8}$.

\section{Preparo das válvulas por engenharia de tecidos}

Seis semanas antes do implante de uma válvula preparada por engenharia de tecidos, um segmento de veia, de 10 a $15 \mathrm{~cm}$ de comprimento, é retirado de cada um dos carneiros jovens utilizados no experimento (fig. 1) ${ }^{9,10}$. As células endoteliais são retiradas dos segmentos venosos por meio de colagenase P 0,1\% (Boehringer Ingelheim Pharmaceuticals, Conn.) e colocadas em um incubador umidificado à temperatura de $37^{\circ} \mathrm{C}$, saturação de $5 \%$ de $\mathrm{CO}^{2}$ e $98 \%$ de ar, por $15 \mathrm{~min}$. As células endoteliais são cultivadas durante quatro semanas no meio Eagle modificado por DulBecco (DMEM, Sigma Chemical Co., St. Louis, Mo) com antibióticos (penicilina $100 \mathrm{U} / \mathrm{ml}$, estreptomicina $100 \mu / \mathrm{ml}$ e anfotericina B $250 \mathrm{ngm} / \mathrm{ml}$, Sigma Chemical, St. Louis, Mo), 20\% de soro de carneiro autólogo e bFGF $5 \mu \mathrm{g} / \mathrm{ml}$ (Boehringer Ingelheim Pharmaceuticals, Ridgefield, Conn.). O meio de cultura era mudado a cada $2^{\circ}$ dia e o crescimento das células endoteliais avaliado, diariamente, em exame microscópico Valvas pulmonares porcinas são preparadas com detergentes químicos para se tornarem matrizes decelularizadas. É realizado exame macroscópico das valvas pulmonares e cada uma é submetida a controle bacteriológico. Depois da preparação e controle da ausência de fenestrações nas cús- 


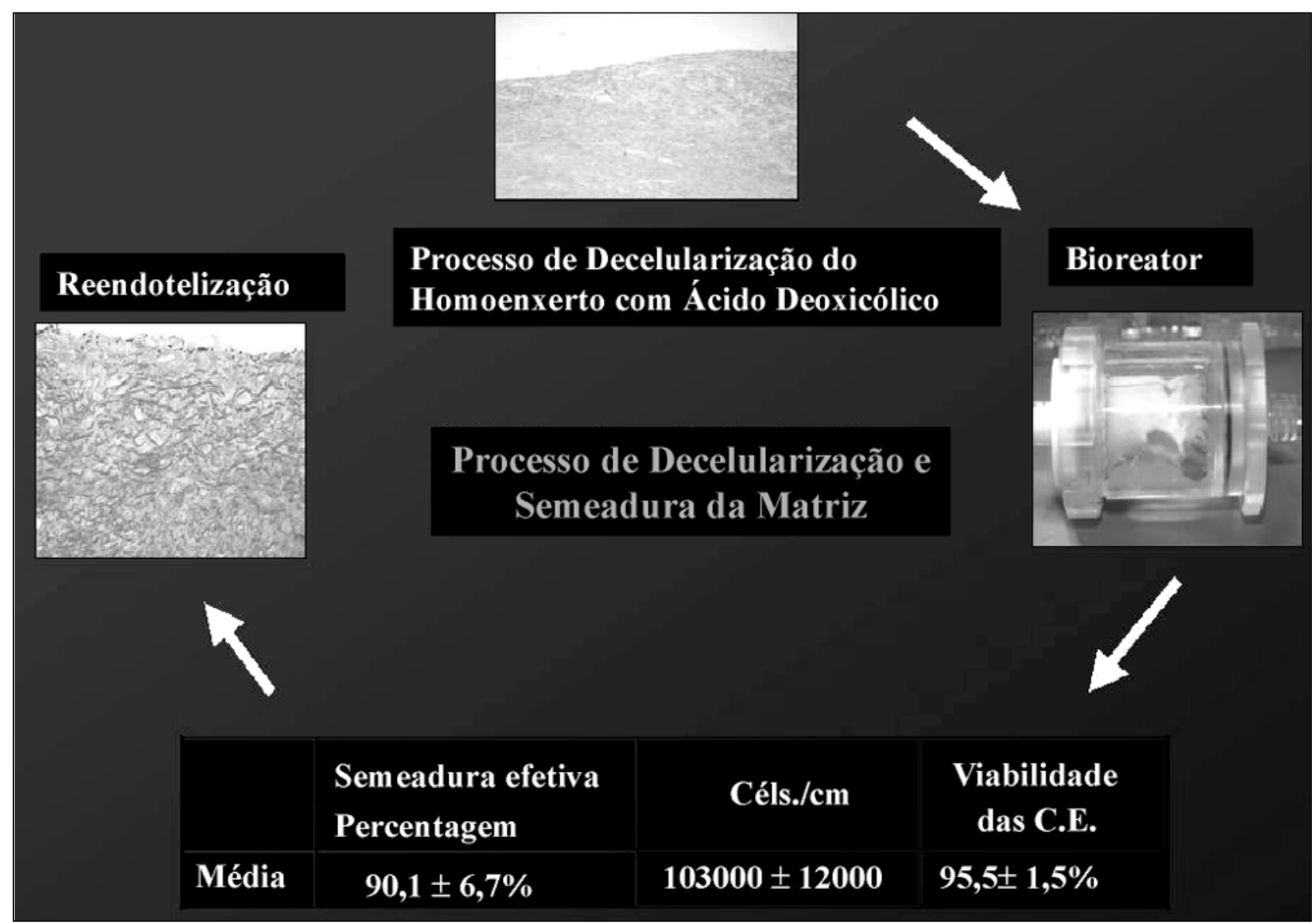

Fig. 1 - Etapas do processo de criação de uma valva cardíaca por engenharia de tecidos. Inicialmente um segmento de veia é retirado, as células endoteliais colhidas são cultivadas, expandidas e caracterizadas. A semeadura de uma matriz decelularizada é seguida pelo implante da valva obtida por engenharia de tecidos.

pides, as valvas são medidas e submetidas a teste de competência. Testes de resistência à ruptura são conduzidos para avaliar a estabilidade das matrizes decelularizadas ${ }^{11,12}$.

As células endoteliais são semeadas na superfície interna da matriz acelular.

Imersão de $3 \mathrm{~h}$ em fibronectina (Boehringer Ingelheim Pharmaceuticals Inc., Ridgefield, Conn.) é feita para aumentar o potencial de adesão das células endoteliais à matriz acelular, de maneira bidimensional, por um período de $4 \mathrm{~h}^{13}$. As valvas cardíacas semeadas são conservadas em solução de Hanks a $4^{\circ} \mathrm{C}$ por até sete dias.

\section{Implante das valvas cardíacas obtidas por en- genharia de tecidos em carneiros jovens}

Uma minitoracotomia esquerdaé feita no $2^{\circ}$ intercosto ${ }^{14,15}$. O pericárdio é incisado, verticalmente, a fim de expor o coração. O tronco pulmonar é isolado e canulado para perfusão arterial, e o átrio direito para retorno venoso. A valva pulmonar tratada por engenharia de tecidos é interposta, tomando-se extremo cuidado para não tocar sua superfície interna As valva pulmonares tratadas por engenharia de tecidos foram explantadas após sete dias, três e seis meses $(\mathrm{n}=8)$. A minitoracotomia esquerda é reaberta e o coração liberado. As próteses explantadas são inspecionadas, macroscopi- camente, e fotografadas a cores. Atenção especial é dedicada à retração das cúspides, fenestrações dos folhetos e material trombótico, em qualquer ponto das valvas. Cada enxerto é seccionado, longitudinalmente, no nível das comissuras, incluindo parte das paredes da artéria pulmonar do carneiro em ambos os lados.

\section{Resultados}

A valva cardíaca modificada por engenharia de tecidos - Depois de quatro semanas o número médio de células endoteliais disponíveis para semear as valvas porcinas decelularizadas era de $58.35 \times 106$ (limites $25,74 \times 106-108,64 \times$ 106). $O$ diâmetro das valvas no ânulo interno $(\mathrm{n}=8)$ variou entre $19 \mathrm{e} 23 \mathrm{~mm}$ (mediana $21 \mathrm{~mm}$ ). A cobertura celular média foi de $1.1 \times 105$ células/cm de superfície (limites 1.0x105-1.2x 105 células/cm de superfície). A viabilidade celular foi de 95.45\% a 97.7\% (mediana 96.8).

\section{Exame macroscópico}

As valvas obtidas por engenharia de tecidos mostraram, após três e seis meses de implante, em ambos os lados das anastomoses, um crescimento fibroso sem encapsulamento das cúspides. Não se encontraram vegetações, he- 
matomas ou material trombótico no enxerto. Os folhetos não mostraram rupturas, perfurações, formação de panus fibrosos, deformidade cuspidal, retração ou enrijecimento.

\section{Calcificação tecidual}

O conteúdo de cálcio foi semelhante em todas as valvas. As porções divididas dos folhetos mostraram um conteúdo médio de cálcio de $2,43 \mu \mathrm{g} / \mathrm{mg}$ de tecido seco, nas áreas comissurais, e 2.20(1.18-3.65) $\mu \mathrm{g}$ de tecido seco na porção basale 2.49(1.26-3.70) $\mu \mathrm{g}$ de tecido seco na margem livre da cúspide.

\section{Histologia}

Microscopia ótica - Não se encontrou calcificação nas cúspides explantadas das valvas obtidas por engenharia de tecidos. A montante das valvas somente uma mínima calcificação estava presente na linha de sutura. No trato de saída, uma mínima porção da parte interna da média estava calcificada. Uma fina camada de tecido fibroso cobria as porções de entrada e de saída das anastomoses entre a valva obtida por engenharia de tecidos e a artéria pulmonar nativa. Não havia crescimento fibroso nas cúspides de nenhuma das valvas examinadas. Na porção externa das valvas cardíacas havia reação inflamatória normal. $\mathrm{Na}$ face luminal da valva havia uma camada monoestratificada de células endoteliais, que alcançava a porção média da cúspide (fig. 2). Dali em diante, apenas ilhotas de células endoteliais foram vistas e não foram encontradas células endoteliais nas margens livres das cúspides (fig.3).

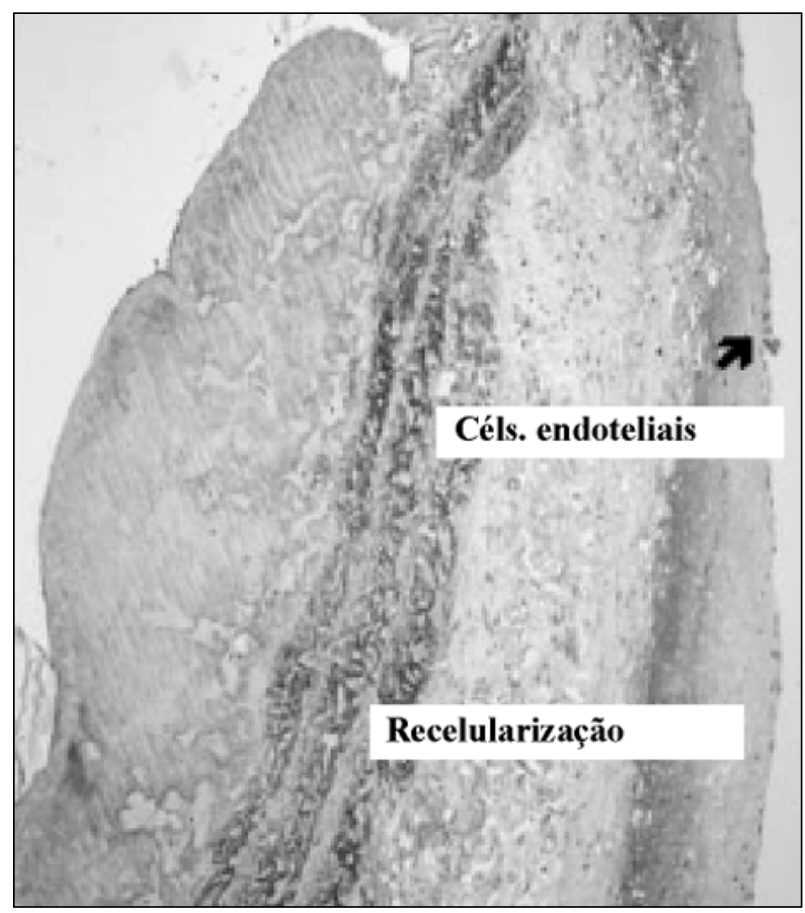

Fig. 2 - Avaliação histológica da porção média de um folheto obtido por engenharia de tecidos, mostrando uma confluência monoestratificada de células endoteliformes na superfície luminal e crescimento de células intersticiais para o interior da matriz.

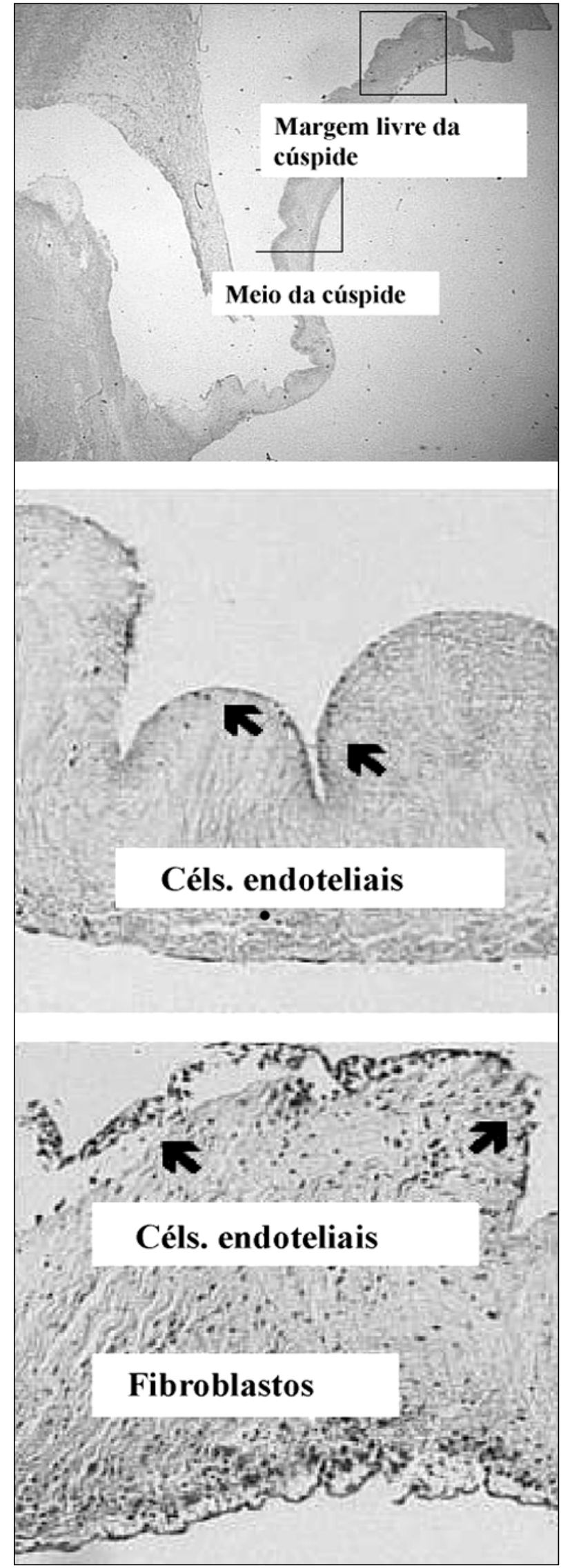

Fig. 3 - Avaliação histológica da margem livre da valva criada por engenharia de tecidos, mostrando ilhas de células endoteliformes na superfície luminal do folheto e poucas células intersticiais crescendo para o interior da matriz. 
Microscopia eletrônica de varredura - Microscopia eletrônica de varredura foi usada para demonstrar a confluência da camada monoestratificada de células de aspecto endotelial na face luminal das valvas obtidas por engenharia (fig. 4) de tecidos. Os achados da microscopia ótica foram confirmados, mostrando apenas ilhotas de células endoteliformes nas margens livres das cúspides.

Microscopia eletrônica de transmissão - Células endoteliformes foram visíveis na superfície interna das valvas obtidas por engenharia de tecidos examinadas aos sete dias, três e seis meses. Com este método de investigação foi possível identificar células intersticiais incorporando as matrizes. Morfologia típica de fibroblastos foi vista com bom desenvolvimento de um retículo endoplásmico grosseiro (fig. 5).

Imuno-histoquímica - A camada monoestratificada de células da superfície interna das valvas foram identificadas como endoteliais pela positividade coloração pelo fator VIII (fig. 6).

\section{Experiência clínica}

No Hospital Charité da Universidade Humboldt de Berlim, de maio a dezembro de 2000 , seis pacientes receberam próteses obtidas por engenharia de tecidos, depois de obtida a aprovação do Comitê de Pesquisas e declarações de consentimento informado.

As valvas assim obtidas, por engenharia de tecidos, foram usadas para substituir o trato de saída do ventrículo direito durante a substituição da valva aórtica pela técnica de Ross ${ }^{16}$.

A média de idade dos pacientes foi $43,8 \pm 9,2$ anos. Os enxertos foram utilizados durante a operação de Ross, para reconstruir o trato de saída do ventrículo direito. O diâmetro interno das matrizes decelularizadas dos homoenxertos foi de $27 \mathrm{~mm}$. A densidade de semeadura foi de $9.5 \times 106$ células $/ \mathrm{cm}$.

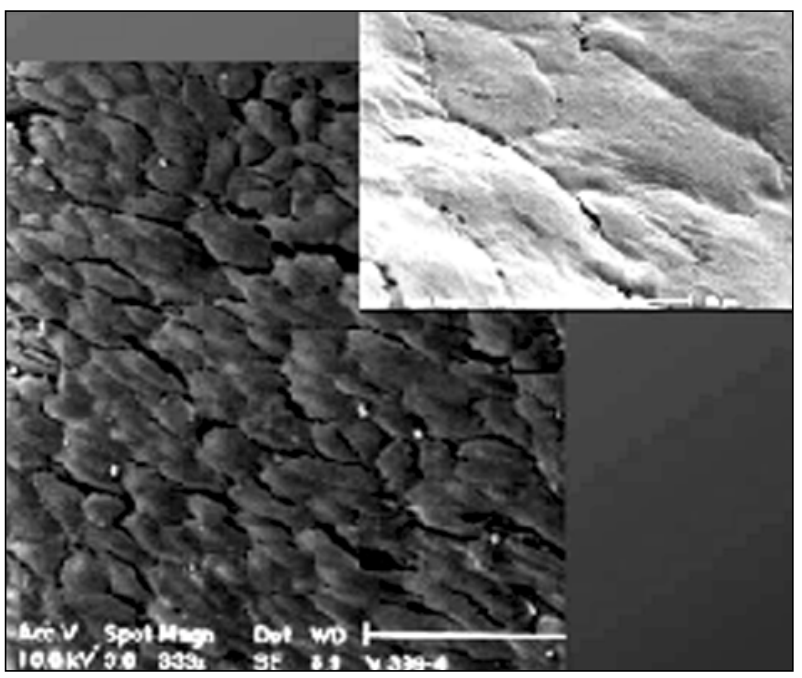

Fig. 4 - Uma camada monoestratificada confluente de células endoteliformes é vista na superfície interna da valva obtida por engenharia de tecidos.

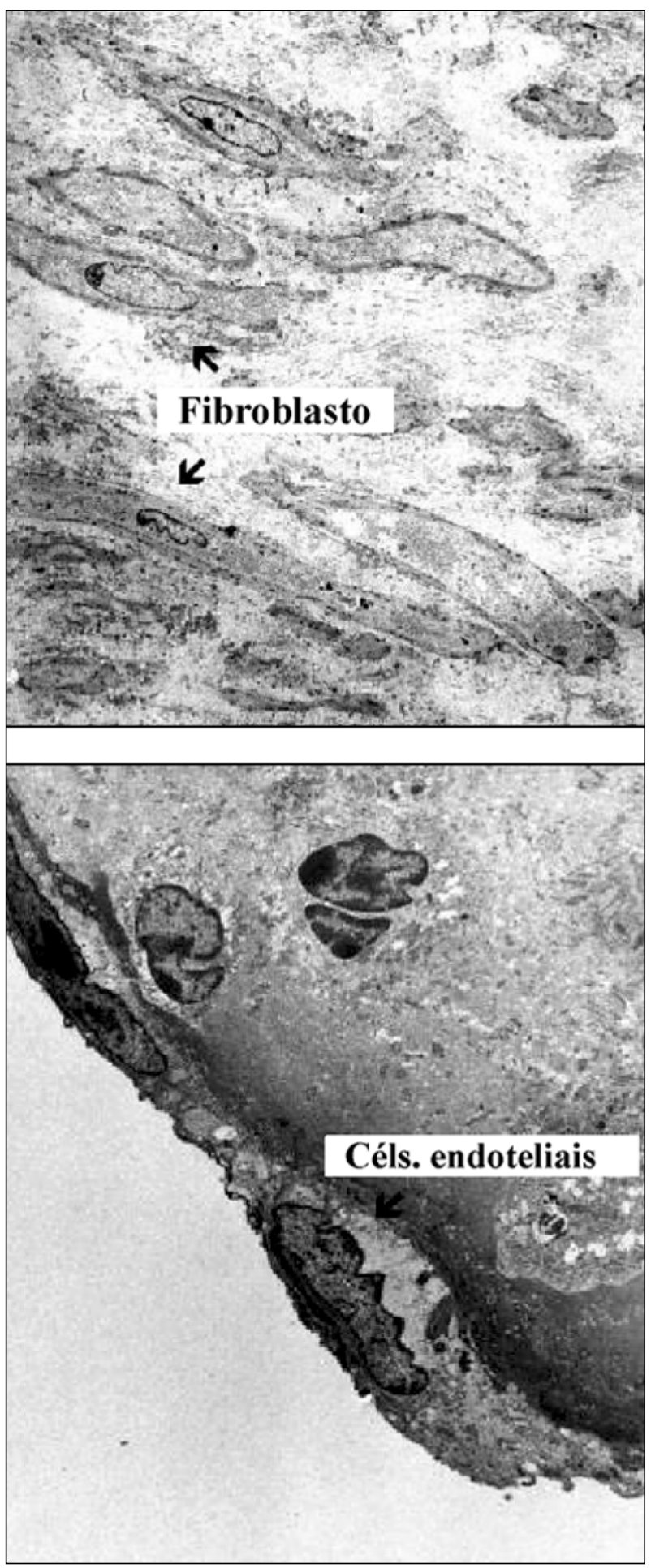

Fig. 5 - Avaliação por microscopia eletrônica de transmissão, mostrando a incorporação de fibroblastos na matriz decelularizada, com um retículo endoplásmico espesso e bem desenvolvido.

O acompanhamento foi feito por ecocardiografia. $\mathrm{Na}$ alta, o gradiente médio da valva aórtica foi de $4,7 \mathrm{mmHg}$ $(1,8-7,2 \mathrm{mmHg})$ e, aos 3 meses, $6,2 \mathrm{mmHg}(1,6-13,5 \mathrm{mmHg})$, sem sinais de regurgitação valvar. $O$ gradiente médio das valvas obtidas por engenharia de tecidos foi $2,2 \mathrm{mmHg}(1,3-$ $3,8 \mathrm{mmHg})$ na alta e, 3 meses depois, $1,5 \mathrm{mmHg}(2,9-$ 


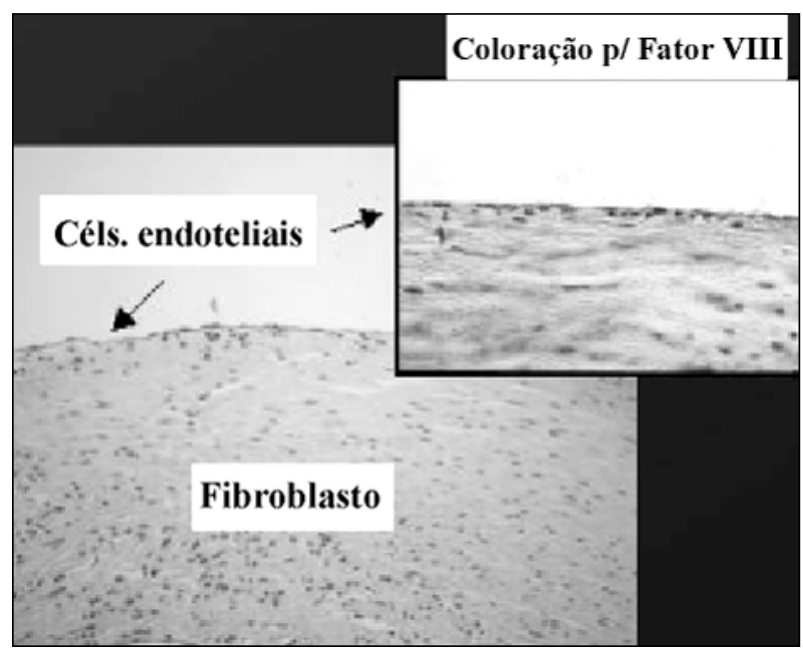

Fig. 6 - Coloração positiva para o fator VIII confirma que as células da camada monoestratificada da face luminal da valva obtida por engenharia de tecidos são endoteliais. Notar a repopulação esponjosa

$1,1 \mathrm{mmHg}$ ), com regurgitação trivial em um caso. A fração de ejeção do ventrículo esquerdo, na alta foi de $58 \pm 13,6 \%$ e, aos 3 meses, $65,2 \pm 9,5 \%$.
Todos os pacientes estavam em grau funcional I da NYHA, por ocasião do último controle.

\section{Conclusões}

Os excelentes achados experimentais no modelo ovino embasaram o uso desta prótese valvar em pacientes selecionados para serem submetidos ao procedimento de Ross.

Estudos sobre a segurança do uso de heteroenxertos, como potenciais matrizes para semeadura de células autólogas, não estão completos. Neste momento, utilizamos homoenxertos decelularizados em pacientes, para contornar o problema dos retrovírus porcinos (PERV) que tem de ser eliminado antes que aquelas matrizes possam ser utilizadas em pacientes. A evolução a curto prazo nos encorajou a iniciar o uso dos homoenxertos decelularizados, para melhorar a qualidade de vida dos pacientes, com o escopo de que eles possam receber essas próteses valvares sem degeneração.

Observações mais longas devem ser realizadas para avaliar o uso futuro desta nova geração de valvas cardíacas que são estruturas vivas.

\section{Referências}

1. Schoen FJ. Approach to the analysis of cardiac valve prostheses as surgical pathology or autopsy specimens. Cardiovasc Path 1995; 4: 241-55.

2. Schoen FJ. Cardiac valve prostheses: pathological and bioengineering considerations. J Card Surg 1987; 2: 65-108.

3. Notzold A, Droste DW, Hagedorn G, et al. Circulating microemboli in patients after aortic valve replacement with pulmonary autografts and mechanical valves prostheses. Circulation 1997; 96: 1843-6.

4. Kouchoukos NT, Davilla-Roman VG, Spray TL, et al. Replacement of the aoertic root with pulmonary autograft in children and yong adults with aortic valve diseases. N Eng J Med 1994; 330: 1-6.

5. Rupprah G, Thuer O, Vogt J, et al. The durability of bioprostheses in young people. Long-term results with intra or extracardiac implanted porcine valves. J Cardiovasc Surg Torino 1985; 26: 251-7.

6. Chistakis G, Joyner C, Morgan C, et al. Left ventricular mass regression early after aortic valve replacement. Ann Thor Surg 1996; 62: 1084-9.

7. Ozaki S, Dohmen PM, Flameng W, et al. Superiority of tissue-engineered heart valves to stentless porcine aortic bioprostheses. Artif Organs 2001; 25: 846-9.
8. Dohmen PM, Ozaki S. Yperman J, et al. Hemodynamic evaluation of a tissueengineeed valve prosthesis. Artif Organs 2001; 25: 843-5.

9. Dohmen PM, Meuris B, Flameng W, et al. Transport of vein material for coating auto-xenograft. Artif Organs 2000; 23: P125.

10. Dohmen PM, Meuris B, Flameng W, etal. Influence of ischemic time and temperature on endothelial cell growth after transport. Int J Artif Organs 2001; 24: 281-5.

11. Dohmen PM, Scheckel M, Stein-Konertz M, et al. In vitro hemodynamics of a novel three leaflet heart valve. Int J Artif Organs 2001; 24: 558-61.

12. Dohmen PM, Stein-Konertz M, Erdebruegger W, et al. A new pulsatile bioreactor for in vitro seeding and conditioning endothelial cells tissue-engineered heart valves. Int J Artif Organs 2001; 24: 557-61.

13. Dohmen PM, Ozaki S, Verbeken E, et al. Tissue engineering of a pulmonary xenograft heart valve. Asian Cardiovasc Thoracic Surg 2002; 10: 25-30.

14. Dohmen PM, Ozaki S, Verbeken E, et al. Tissue-engineered auto-xenograft heart valve. J Cardiovasc Surg 2000; (Suppl I): 1-35.

15. Dohmen PM, Braun J, Konertz W. Early postoperative difference between tisue engineered allografts and regular allografts. Circulation 2001 (in press). 